\title{
History of Liquid Crystals Goes from Cloudy to Clear
}

Liquid crystalline materials display a degree of structural order intermediate between that of crystals and that of isotropic liquids. When samples of liquid crystals were first examined in the mid1800 s, they were not immediately recognized as a novel and exotic phase of matter. For instance, a chemist investigating the properties of natural fats noticed that one material, stearin, appeared to have two distinct melting points. The first transition was from solid to a cloudy liquid, and the second from cloudy to clear liquid. One possible explanation for such behavior could be the presence of an impurity that gives rise to a two-phase coexistence region in the phase diagram, so it was not immediately obvious that the cloudy liquid was anything remarkable.

Another set of early observations in the mid- to late-1800s involved the use of polarized light. Crystals can alter light's polarization, and the effect changes dramatically when a crystal sample is rotated with respect to the light beam. Most liquids have no effect on polarization; liquids containing chiral molecules can alter light's polarization, but the effect shows no variation with rotation of the sample. Thus it was an important discovery that certain biological materials such as the outer covering of a nerve fiber mixed with water could produce changes in light's polarization, and that the effect varied with the angular orientation of the sample. This was perhaps the first clear evidence that such liquids are not isotropic but contain some kind of directional order. A few researchers also noted that some compounds synthesized from cholesterol briefly turned bright blue as they cooled, an effect that was not fully explained until nearly a century later.

A German physicist, Otto Lehmann, was the first scientist to construct a microscope with a heating stage, and later added polarizers. Lehmann's goal was to observe the process of crystallization, and using his microscope he saw that some materials appeared to have an intermediate amorphous phase between crystal and liquid. In 1888 an Austrian botanist, Friedrich Reinitzer, found that an organic material closely related to cholesterol had two distinct melting points, and wondered what the intermediate cloudy liquid phase could be. He sent samples to Lehmann, who examined them in his microscope.
Lehmann concluded that the liquid was a uniform fluid phase-not a two-phase mixture-and observed that it affected polarized light as a crystal would. Thus he coined the name "liquid crystal."

Daniel Vorlander, a chemist, headed a group that went on to synthesize many liquid crystalline materials, including the first material known to have two distinct liquid crystalline phases. He realized that materials whose molecules were linear and elongated in shape were the most likely to display liquid crystalline phases. Within a few decades the major classes of liquid crystal phases were known. In a 1922 paper, Georges Freidel of France outlined the basic structure of nematic, smectic, and cholesteric phases. In the isotropic liquid, molecules point in all directions, while in the nematic phase, the molecules tend to align with one another. The local alignment direction is called the director. The name "nematic" is derived from the Greek word for "thread," and refers to the threadlike defects observed in the director when a sample is viewed in a microscope with crossed polarizers. From careful study of defect structures, Freidel concluded that the smectic phase had not only directional order but also layering. The name smectic is derived from the Greek word for "soap," as smectic phases have material properties similar to those of soap. The cholesteric phase, also known as the chiral nematic phase, displays local alignment of molecules as in the nematic, but with the local

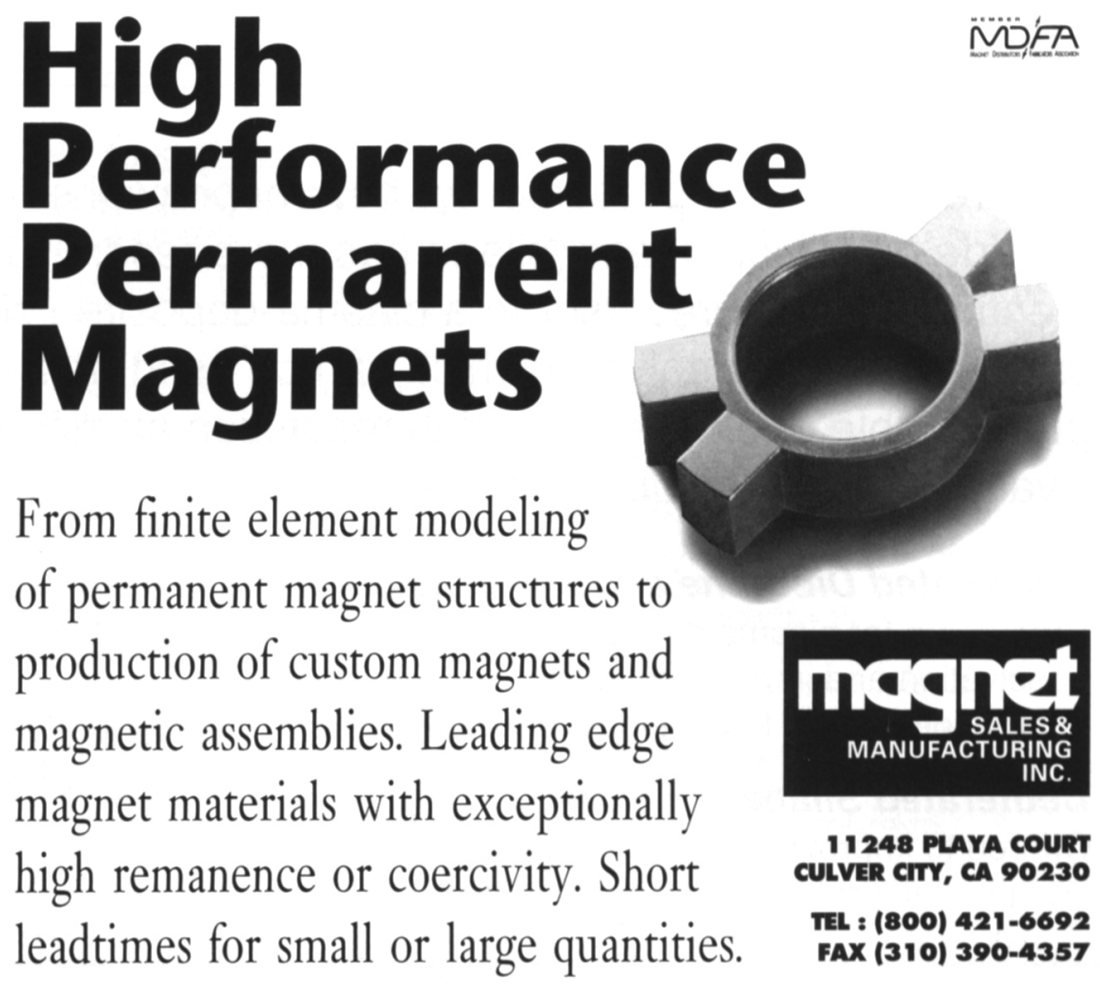

Circle No. 44 on Reader Service Card.

Visit MRS Exhibit Booth No. U207 
director orientation undergoing a periodic twist along one direction. This name was chosen because various materials closely related to cholesterol can take on this phase. Freidel also understood that liquid crystals could be affected by applied electric and magnetic fields, a property that is critical to their use in display devices.

In the years prior to World War $\Pi, x$-ray scattering experiments verified unambiguously the presence of directional ordering in liquid crystalline materials, and theoretical studies like those made by F.C. Frank in England provided explanations for the forms of the various phases. But by the end of World War II, most researchers lost interest in studies of liquid crystals for lack of any obvious technical application.

The field blossomed again in the 1960s, as an accurate microscopic theory of liquid crystal phases was developed by Wilhelm Maier and Alfred Saupe of Germany, and researchers at RCA invented the first liquid crystal display (LCD) by switching a liquid crystal from cloudy to clear by the applica tion of an electric field. LCDs were used in digital watches, calculators, and clocks, and in recent years also for computer displays, telephones, and televisions. The most common display method since the 1970 s has been the "twisted nematic," in which a nematic phase material is confined between glass sheets treated to align the director with a 90 degree twist between one sheet and the other. Crossed polarizers are placed above and below, and a reflector beneath. When no electric field is applied, the twisted nematic rotates the polarization of ambient light so that the light is reflected, giving the display a silvery appearance. When an electric field is applied, the alignment of the nematic changes the polarizing effect so that ambient light is absorbed rather than reflected, and the display appears to be black. More advanced technologies make use of other liquid crystalline phases; ferroelectric liquid crystals can provide superior response time and improved contrast and viewing angle.

Modern developments have included the discovery of discotic liquid crystals, composed of flat, disklike molecules, and the development of polymer liquid crystals, such as Kevlar, which is formed from a liquid crystal phase of polyamide and is used in tires and bullet-proof vests. The bright blue colors first observed in cooling cholesterol-like materials in the $1880 \mathrm{~s}$ were finally identified in the 1980 s as unusual "blue phases" consisting of a liquid crystal with a lattice of defect lines whose periodicity is comparable to the wavelength of light. Liquid crystal science has also produced windows that can be switched electrically from clear to opaque. Liquid crystal phases of biomaterialssuch as those first observed in the late 1800 s - continue to be discovered, including solutions of DNA, polypeptides, and lipids.

ROBIN L. BLUMBERG SELINGER

For Further Reading: P.J. Collins, Liquid Crystals: Nature's Delicate Phase of Matter, Princeton University Press (Princeton, 1990).

\begin{tabular}{|c|c|}
\hline & $\begin{array}{l}\text { Other VOLTAIX } \\
\text { Products: } \\
\text { (Applications) }\end{array}$ \\
\hline $\begin{array}{l}\text { High Purity Methylsilane } \\
\text { First reported as a precursor for heteroepitaxial silicon } \\
\text { carbide on silicon, methylsilane has more recently been } \\
\text { identified as the precursor to a plasma-deposited silicon- } \\
\text { carbon-hydrogen polymer which can be used as a dry } \\
\text { processable photoresist for high resolution applications. } \\
\text { Available in limited quantities with } \geq 99.9 \% \text { purity. }\end{array}$ & $\begin{array}{l}\text { Germane, Digermane } \\
\text { (a-Si, heteroepi-Si) } \\
\text { Diborane, Phosphine } \\
\text { (BPSG, a-Si, epi-Si) } \\
\text { Silane, Disilane } \\
\text { (a-Si, epi-Si) } \\
\text { Trimethylboron } \\
\text { (BPSG, a-Si) }\end{array}$ \\
\hline $\begin{array}{l}\text { Deuterated Diborane and Trimethylboron } \\
\text { Precursors for plasma deposited Tokomak wall } \\
\text { passivation and impurity gettering coatings, in the } \\
\text { international effort to develop hot fusion energy. }\end{array}$ & ler \\
\hline $\begin{array}{l}\text { Deuterated Silane } \\
\text { Offered to improve the performance of silane derived } \\
\text { silica for integrated optical waveguides. } \\
\text { O1993 voLTAI, INC. }\end{array}$ & $\begin{array}{l}\text { anch, NJ } 08876 \\
-9060\end{array}$ \\
\hline
\end{tabular}

Vlsit MRS Exhibit Booth No. U311
This is an"INFOTISEMENT" from Voltaix, Inc.

Your comments or questions are most welcome. 


\section{○XF O R D UIVERSITY PRESS}

\section{INTRODUCTION TO BIOENCINEERING}

S. A. Berger, W. Goldsmith, and E. R. Lewis

Contributions from instructors in mechanical, electrical, chemical, and nuclear engineering mirror fundamental engineering science as applied to problems in the biological world. October 1996544 pp.; 400 illus. $\$ 110.00$

\section{INTRODUCTORY}

\section{STATISTICAL MECHANICS}

Roger Bowley and Mariana

Sánchez

"This will be a much welcomed book by all physics and chemistry undergraduates studying the subject."

-Physics World Magazine.

1996304 pp.; 63 illus.

paper $\$ 29.95 /$ cloth $\$ 59.95$

\section{RARE-EARTH IRON PERMANENT MAGNETS}

Edited by J. M. D. Coey

This book covers the principles of permanent magnetism, magnet processing, and applications in a series of interlocking chapters written by experts in each area.

(Monographs on the Physics and Chemistry of Materials 54)

October 1996704 pp.; 324 illus. $\$ 135.00$

\section{CONVECTIVE BOILING AND CONDENSATION}

\section{Third Edition}

John G. Collier and John R.

Thome

"The excellent material added by Dr.

Thome will considerably broaden the appeal of this well accepted book. It should remain a key reference on two-phase flow and heat transfer." - Heat Transfer Engineering.

(Oxford Engineering Science Series 38) 1994 (paper 1996) 640 pp.; 207 illus. paper $\$ 70.00 /$ cloth $\$ 165.00$

\section{HANDBOOK OF LIOUID CRYSTAL RESEARCH}

Edited by Peter J. Collings and Jay S. Patel

Liquid crystal technology is one of the most important developments in today's world. The book covers both theory and practice, explaining the processes that govern liquid crystals and their scientific and technological applications.

December 1996608 pp.; 638 illus. $\$ 195.00$

\section{THE MATHEMATICS OF DEFORMABLE SURFACES}

Edited by D. G. Dritschel and R. J. Perkins

This collection of papers, presented at a recent Institute of Mathematics and its Applications conference, covers different aspects of the changes in surfaces (metals, materials, water) as a result of physical forces.

(The Institute of Mathematics and its

Applications Conference Series, New Series 56)

1996264 pp.; 100 illus.

$\$ 140.00$

\section{THE BASICS OF CRYSTALIOGRAPHY AND DIFFRACTION}

Christopher Hammond

In this new text, basic ideas in crystallography and diffraction are explained simply and comprehensively. The physical concepts and geometrical features common to diffraction modes are emphasized by simple analogies and demonstrations. (International Union of Crystallography Texts on Crystallography 3)

March 1997256 pp.; 180 illus. paper $\$ 24.95 /$ cloth $\$ 55.00$

\section{ATOM PROBE FIELD ION MICROSCOPY}

M. K. Miller, A. Cerezo, the late M. G. Hetherington, and G. D. W. Smith

The atom probe technique is one of the most important experimental methods in the emerging field of atomic-scale science and technology. This book gives a definitive, up-todate account of the field.

(Monographs on the Physics and Chemistry of Materials)

November 1996672 pp.; 221 illus. $\$ 120.00$

\section{NUCLEAR MAGNETIC RESONANCE SPECTROSCOPY IN ENVIRONMENT CHEMISTRY}

Edited by Mark A. Nanny, Roger A. Minear, and Jerry A. Leenheer This book demonstrates the usefulness of NMR spectroscopy to a wide variety of topics in environmental science and technology. It presents research involving numerous nuclei in highly heterogeneous and complex samples.

(Topics in Environmental Chemistry) February 1997384 pp.; 112 illus. $\$ 65.00$

\section{DATA ANALYSIS \\ A Bayesian Tutorial}

D. S. Sivia

Takes the mystery out of statistics by showing how a few fundamental rules can be used to tackle a wide variety of problems in data analysis.

1996240 pp.; 50 illus.

paper $\$ 29.95 /$ cloth $\$ 65.00$

\section{THE PHYSICS AND APPLICATIONS OF PHOTOREFRACTIVE MATERIALS}

L. Solymar, D. J. Webb, and A. Grunnet-Jepsen

This book summarizes all the advances in this field in a manner that provides both a good introduction for beginning students and a detailed account for more experienced researchers.

(Oxford Series on Optical and Imaging Sciences

October 1996512 pp.; 247 illus.

$\$ 135.00$

Circle No. 27 on Reader Service Card. 


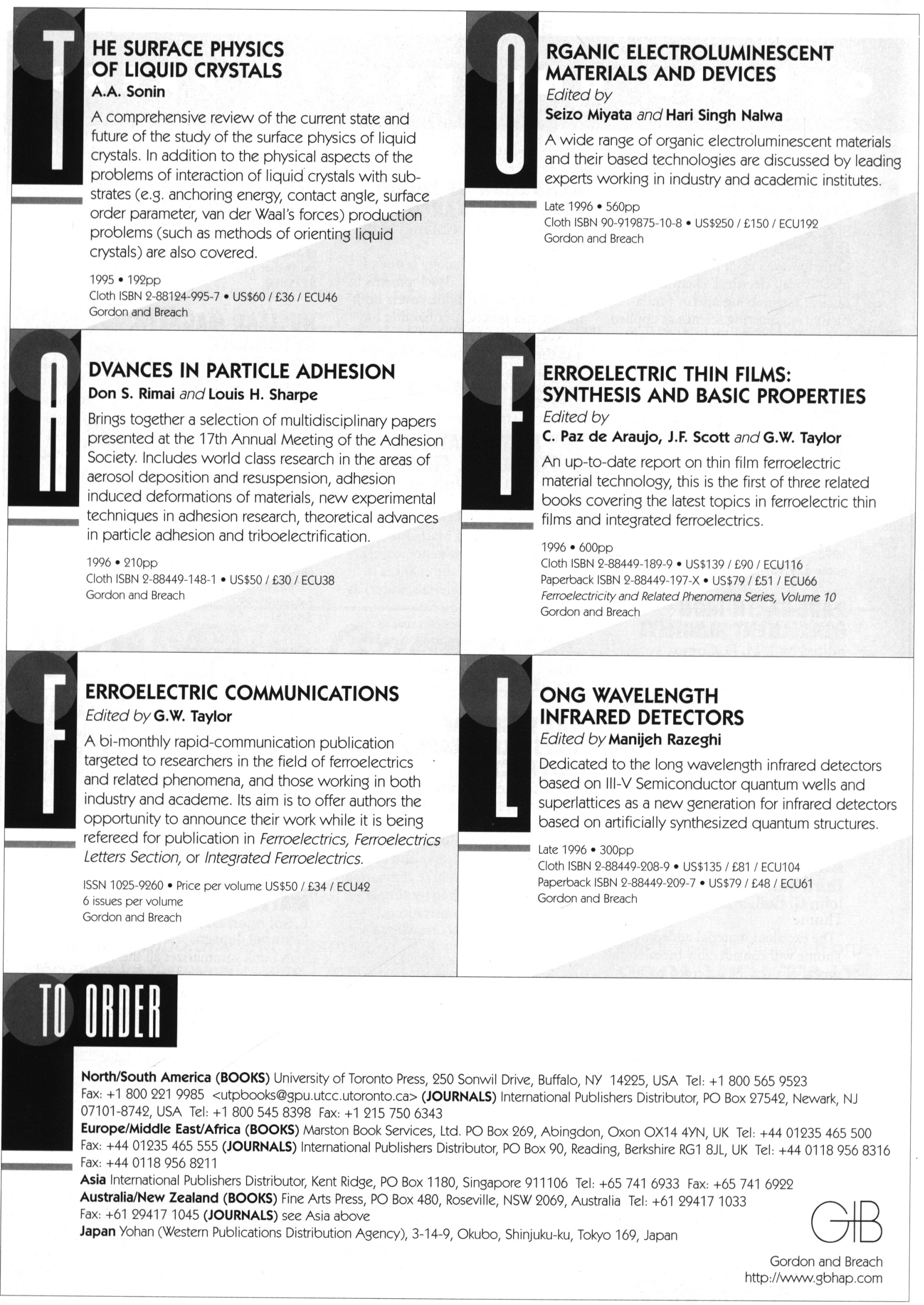




\section{The Science of} Polymer Molecules

Richard H. Boyd and

Paul J. Phillips

"... a welcome addition to the scientific literature in general and to the Cambridge Solid State Science Series... an exceptionally interesting and useful book..."

-Polymer News and Computational

Polymer Science

Focusing on the synthesis, structure and properties of the individual molecules that constitute polymeric materials, this text approaches the subject matter from a molecular basis and develops principles from an elementary starting point.

Cambridge Solid State Science Series $1996428 \mathrm{pp}$.

56508-1 Paperback $\$ 32.95$

\section{Permanent Magnet Materials and their Application Peter Campbell}

The core of the book is a detailed treatment of the methods used to design permanent magnets, including assessments of the changes they experience under practical operating conditions. The volume also describes modern analytical techniques including the finite element method, with reference to the accurate simulation of permanent magnetic materials.

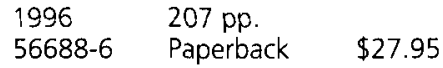

\section{Reflection Electron} Microscopy and Spectroscopy for Surface Analysis

\section{Zhong Lin Wang}

This book is a comprehensive review of the theories, techniques and applications of reflection electron microscopy (REM), reflection high-energy electron diffraction (RHEED) and reflection electron energyloss spectroscopy (REELS). Contains much invaluable reference material, including FORTRAN source codes for calculating crystal structures data and electron energy loss spectra in different scattering geometries.

$1996 \quad 455 \mathrm{pp}$.

48266-6 Hardback

$\$ 95.00$
UV Lasers: Effects and Applications in Materials Science W.W. Duley

This volume provides the first comprehensive overview of the modern use of ultraviolet laser radiation in the processing of materials.

1996

$418 \mathrm{pp}$.

46498-6

Hardback

$\$ 95.00$

\section{Physical Metallurgy}

Third Edition

\section{Paul Haasen}

The third edition includes new sections on the permeation of hydrogen in metals, the Landau theory of martensitic transformation, and order hardening and plasticity of intermetallics. Numerous other sections have been brought up to date in the light of many new developments.

$\begin{array}{lll}1996 & 436 \text { pp. } & \\ 55092-0 & \text { Hardback } & \$ 125.00 \\ 55925-1 & \text { Paperback } & \$ 44.95\end{array}$

\section{An Introduction to} Composite Materials Second Edition

\section{Hull and \\ T. W. Clyne}

This new edition's coverage has been increased to include polymeric, metallic and ceramic matrices and reinforcement in the form of long fibers, short fibers and particles. Designed as a teaching text, it will also be an excellent source book for academic and technological researchers. Cambridge Solid State Science Series

$\begin{array}{lll}1996 & 342 \text { pp. } & \\ 38190-8 & \text { Hardback } & \$ 90.00 \\ 38855-4 & \text { Paperback } & \$ 34.95\end{array}$

\section{An Introduction to} X-ray Crystallography

Second Edition

\section{Michael M. Woolfson}

All major aspects of crystallography are covered-the geometry of crystals and their symmetry, theoretical and practical aspects of diffracting $\mathrm{X}$-rays by crystals and how the data may be analyzed to find the symmetry of the crystal and its structure. 1996

Hardback \$99.95 42359-7 Paperback \$39.95

\section{Bose-Einstein} Condensation

A. Griffin,

D.W. Snoke, and

S. Stringari, Editors

"... a valuable reference for both those in the field and those who want to understand the physics behind this fascinating new state of matter."

-Thomas Greytak, Physics Today

This book is devoted to BEC as an interdisciplinary subject, covering atomic and molecular physics, laser physics, low temperatures, and astrophysics

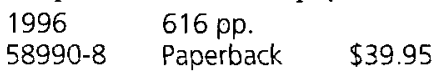

\section{Stability of}

Microstructure in Metallic Systems

Second Edition

J.W. Martin,

R.D. Doherty, and

B. Cantor

In investigating the various causes of thermodynamic instability in metallic microstructures, this text examines current understanding of the kinetics behind structural change in metals.

The new edition has been completely updated and includes a completely new chapter on highly metastable alloys. Cambridge Solid State Science Series

$\begin{array}{lll}1996 & 368 \text { pp. } & \\ 41160-2 & \text { Hardback } & \$ 100.00 \\ 42316-3 & \text { Paperback } & \$ 39.95\end{array}$

42316-3 Paperback $\$ 39.95$

\section{Conjugated Polymer Surfaces and Interfaces}

Electronic and Chemical Structure of Interfaces for Polymer Light Emitting Devices

\section{W.R. Salaneck,}

\section{S. Stafstrom, and}

\section{J-L. Bredas}

In this book the authors illustrate the basic physics and materials science of conjugated polymers and their interfaces, particularly, but not exclusively, as they are applied to polymer-based light emitting diodes.

$1996150 \mathrm{pp}$

47206-7 Hardback \$49.95
Availuble in

bookstores or firom

\section{AMBRIDGE} UNIVERSITY PRESS
40 West 20th Street, New York, NY 10011-4211 Call toll-free 800-872-7423. Web site: hup://www.cup.org MasterCard/VISA accepted. Prices subject to change 